Shortened Title: Coping with Emotional Labor

\title{
Title: Coping with emotional labor in high stress hospitality work environments
}

\begin{abstract}
Hospitality environments, particularly casino VIP rooms, are often overlooked as "high stress" work environments. Faced with challenging work situations, frontline employees experience tremendous emotional demands during interpersonal interactions. As this leads to emotional exhaustion, frontline employees must find ways of managing emotional labor through coping strategies to reduce its negative impacts. This research explores strategies that VIP room's frontline employees use in coping with emotional demands. The research identifies four families of strategies: opposition, rumination, emotional regulation, and positive cognitive restructuring, corresponding to surface acting, deep acting and genuine emotions, respectively. The study opens new avenues for further understanding of the coping and emotional labor concepts.
\end{abstract}

Keywords: emotional demands; emotional labor; coping; casino VIP rooms 


\section{Shortened Title: Coping with Emotional Labor}

\section{Introduction}

Casinos are key tourism drivers serving various hedonistic experiences (Wong \& Rosenbaum, 2012). Within its depths are exclusive gaming rooms known as "VIP gaming rooms", hosting seasoned "high rollers" accounting for majority of the casino's revenue (Lucas, Kilby, \& Santos, 2002). Casinos impose "display rules" - strict behavioral guidelines for employees - to ensure 'professionalism' and manage relational capital (Ashforth \& Humphrey, 1993; Cheng \& Wong, 2015). To comply with display rules, employees may display emotions that they may not genuinely feel through acting to ensure they are "professional". These employees experience tremendous emotional demands as they amplify positive emotions (e.g. cheerfulness) whilst hiding negative ones (e.g. frustration) through surface or deep acting, potentially increasing their stress levels (Subramony et al., 2017).

Broadly speaking, emotional labor is the management of emotions towards others as part of a work role, and incorporates an integrated process of job emotional requirements, emotional regulation and interpersonal behaviors (Grandey \& Gabriel, 2015). As such, emotional demands that stem from job stress can be seen as a form of emotional labor (Sandiford \& Seymour, 2011). In hospitality environments where interpersonal interactions are the crux of service delivery, emotional demands often lead to burnout, poorer service performance, job dissatisfaction, and potentially turnover intention (Lee, An, \& Noh, 2014). Hence, finding better coping strategies to manage emotional demands is imperative. From a theoretical perspective, emotional labor studies fail to fully understand how individuals manage their emotional demands and subsequently their behaviors during a service encounter (Riley, 2007).

This research addresses literature gaps related to high stress hospitality environments like VIP gaming rooms (Chan, Wan, \& Kuok, 2014). The interaction of high-stakes gambling and first-class guest services expectations cause significant stress as employees must engage 


\section{Shortened Title: Coping with Emotional Labor}

in emotional labor with their guests or superiors. To minimize stress, employees must cope with emotional labor. To date, with the exception of two studies - Pienaar and Willemse (2008) and Tsaur and Tang (2012), both taking a quantitative methodology, tourism and hospitality research has yet to examine the implications of emotional labor for frontline employees' coping strategies. There is a need for hospitality-specific study of coping strategies because these strategies would differ from general coping strategies. The respective differences stem from the high level of interpersonal interaction involved in the hospitality context. In comparison, general coping strategies take into little consideration the interpersonal relationship. Drawing on frontline employees' accounts and researchers' interpretations, we analyze the coping strategies frontline employees use to manage emotional labor in VIP gaming rooms.

\section{Literature Review}

The importance of tackling emotional labor management through coping cannot be stressed enough. Many past studies have shown that emotional exhaustion experienced by the suppression of emotions often leads to negative outcomes such as poorer well-being (i.e. burnout) and job satisfaction (Lee et al., 2014; Lu \& Gursoy, 2013; Sohn, Lee, \& Yoon, 2016). A recent review highlighted how stress management and coping repertoires are necessary to enhance a frontline employee's capabilities and reduce the adverse outcomes of emotional labor and burnout (Jeung, Kim, \& Chang, 2018). Edwards (1992) contended that coping can be activated directly by stress when one anticipates potential harm to his/her wellbeing; and, indirectly by stress once well-being has been affected. For example, burnout arises from emotional demands experienced but coping via well-planned leisure activities reduces burnout (indirect activation) (Pienaar \& Willemse, 2008; Tsaur \& Tang, 2012). By utilizing better coping strategies, frontline employees are better capable of handling their emotions and reducing the negative effects of their job requirements (Cheng, Chang, \& Chan, 


\section{Shortened Title: Coping with Emotional Labor}

2018). However, simply assuming emotional labor (in general) leads to adverse effects is inaccurate as emotional labor can be enacted in different ways, each leading to a specific outcome.

Emotional labor effort often manifests through either surface or deep acting. Surface acting, which requires less emotional effort, means that employees modify or control their emotional expressions, for instance, by faking a smile towards a customer, colleague or superior (Reyers \& Matusitz, 2012). This often causes the frontline employee to experience emotional dissonance as they suppress their actual emotions, resulting in emotional exhaustion and potentially incurring turnover intentions (Brotheridge \& Grandey, 2002; Kenworthy, Fay, Frame, \& Petree, 2014; Lu \& Gursoy, 2013). Deep acting, which requires more emotional effort, occurs when real emotions are elicited to match the required displays (Hoffman, 2016). Frontline employees often feel less dissonance, allowing positive work outcomes to manifest (Chu, Baker, \& Murrmann, 2012). More recent literature raises the possibility of employees displaying their naturally felt emotions, which may coincide with (aligned genuine emotions) or deviate from (deviant genuine emotions) the organization's display rules (Diefendorff, Croyle, \& Gosserand, 2005; Goussinsky, 2015). There is limited empirical evidence on how expressing one's genuine emotions affects emotional well-being and job performance, with some recent research suggesting that displaying genuine emotions could in fact, limit emotional dissonance and deter burnout (Golparvar, 2015; Walsh, 2018). Since the type of emotional labor regulation/display (i.e. surface acting, deep acting, genuine emotions) affects whether emotional dissonance, emotional exhaustion and subsequently turnover intentions are experienced, identifying ways of coping with emotional labor demands becomes beneficial for both the frontline employee and the organization.

\section{Coping with Emotional Labor}




\section{Shortened Title: Coping with Emotional Labor}

Coping is a process that manages demands exceeding a person's emotional capabilities to improve well-being (Amirkhan \& Auyeung, 2007). Unlike emotional labor studies which focuses on the emotional displays and its interpersonal implications, coping research examines how individuals manage their emotions in difficult situations. Effective coping enables better management of emotional labor demands, leading to more positive outcomes for the individuals and the organization (Figure 1).

Please insert Figure 1 about here

The most common coping strategy classification is problem- versus emotion-focused coping (Lazarus \& Folkman, 1984). Problem-focused coping addresses the source of stress by using strategies that generate solutions to the problems. On the contrary, emotion-focused coping targets negative emotions directly. Other scholars differentiate engagement (towards) coping from disengagement (away from) coping (Adan, Antunez, \& Navarro, 2017). Engagement coping 'engages' stress through problem solving, whereas disengagement coping avoids stress. The third coping strategy classification distinguishes primary and secondary control (Morling \& Evered, 2006). Primary control coping actively targets the stressor through emotional regulation. Secondary control coping adapts to stress through cognitive reappraisal. It is found that problem-focused, engagement, primary and secondary control coping lead to better health outcomes compared to disengagement and emotionfocused coping (Compas, Connor-Smith, Saltzman, Thomsen, \& Wadsworth, 2001)

These categorizations are overly simplistic and have been criticized for being dyadic, facing issues when strategies fall between distinctions (Compas et al., 2001). For example, when one is both accepting (secondary control) and actively trying to solve the problem (primary control) or if a person decides to walk away from an issue (disengagement) to find a solution to the issue (engagement). The first consolidation attempt encouraged a non-dyadic hierarchical coping category, identifying 13 higher order coping families followed by their 


\section{Shortened Title: Coping with Emotional Labor}

lower-order coping strategies (Skinner, Edge, Altman, \& Sherwood, 2003) (Table 1).

However, scholars still prefer to conduct research under the dyadic frameworks of coping strategies (Adan et al., 2017; Sanchez, Smith, \& Adams, 2018). There has been little effort to further explore the potential of non-dyadic frameworks such as Skinner et al.'s (2003) study, as well as how one's adoption of coping strategy is affected by the nature of the stress he/she is trying to cope with.

Perceived control forms part of an individual's ability to appraise situations during a stressful encounter, which determines the coping strategies adopted during a stressful situation. It has been attributed to better handling of stress and job tasks (Luchman \& Gonzalez-Morales, 2013). As employees are given more control over their work demands, they cope better with stressful situations. A combination of locus of control (ability to exert influence on situations) and self-efficacy (belief in one's self to efficiently exert influence) allows individuals to handle stressful situations efficiently (Meier, Semmer, Elfering, \& Jacobshagen, 2008). Since perceived control determines a given coping strategy, it could potentially explain which emotional labor strategy (i.e., surface acting, deep acting, and genuine emotions) is also used during a service encounter.

The choice of coping strategies can also depend on different motivations (i.e. prioritized goals individuals aim to achieve) such as competence, relatedness, and autonomy (Skinner et al., 2003). Competence is an individual's motivation to control the problem or outcome (e.g. services provided) (White, 1959). In a service context, competence may be interpreted as a person's ability to perform a service. An employee may engage problem solving (instrumental action) or helplessness (inaction) if the problem threatens their competence (Skinner et al., 2003). Relatedness is one's need to be cared for and connected with others (i.e. relationship with others) (Baumeister \& Leary, 1995), such as customers and colleagues. When relatedness is threatened, the employee may engage support seeking or 


\section{Shortened Title: Coping with Emotional Labor}

isolate themselves further (Skinner et al., 2003). Autonomy is the perception of psychological freedom in one's own actions (e.g. individual well-being) (Visser, 2010). The employee may engage self-encouragement (positive cognitive restructuring) or self-blame (rumination) if the problem threatens their autonomy (Skinner et al., 2003). Ntoumanis, Edmunds, and Duda (2009) reported that the perceived control and motivational priorities may encourage better coping strategies. This proposition while theoretically sound, lacks empirical support. Therefore, this study intends to expand on this proposition and determine whether these priorities do impact on the coping strategies.

Please insert Table 1 about here

Considering the above literature review and identified research gaps, this study aims to extend limited emotional labor research by looking at high stress hospitality environments such as casino VIP gaming rooms. Current emotional labor research has been predominantly focused on understanding how situational circumstances such as abusive guests lead to the adoption of particular emotional labor enactment (e.g., deviant genuine emotions) (Goussinsky, 2015). Research has yet to explore coping as a process and how this process may facilitate the enactment of emotional labor. By incorporating factors such as employee's perceived control into the coping process (Meier et al., 2008), research will be better able to uncover which strategies employees adopt in high stress environments to cope with emotional labor demands. This research also attempts to develop theoretical foundations and empirical evidence to some of the known issues in coping literature. Specifically, it addresses how perceived control and motivational priorities affect the non-dyadic hierarchical coping strategies. Utilizing coping as a foundation to understand emotional labor and how individuals truly manages their emotions for interpersonal transactions can bring more depth to current research on emotional labor. This study therefore asks: 


\section{Shortened Title: Coping with Emotional Labor}

1. What key coping strategies do VIP rooms' frontline employees use to cope with emotional demands?

2. In what circumstances do VIP rooms' frontline employees utilize one coping strategy over another with respect to emotional labor?

\section{Methodology}

The intricacy of human emotions means every individual cope with emotional labor differently (Shani, Uriely, Reichel, \& Ginsburg, 2014) and thus, we adopted an interpretivist approach under a dualistic ontology and subjectivist epistemology (Slevitch, 2011) for close examination of the realities of each participant, giving their personal experience a "voice" (Sloan \& Bowe, 2013). Furthermore, as this research aims to uncover how the participant copes with emotional labor in a high-stress hospitality environment, using the interpretivist philosophy allows us to take into consideration the subjective realities of each participant's lived experiences (Creswell, 2013). Through in-depth interviews, it allowed us to gain insight into the rich complexities of emotional labor coping experiences (Olson, 2011), as questions were tailored to suit the interview situation.

It is imperative to reveal researcher characteristics since the relationship between researcher and subject matter is integral in the interpretive paradigm. The first author/field researcher was born in [location withheld] and resided in [location withheld] for four years. Working in the casino VIP gaming department allowed him to observe significant physical and emotional demands on those servicing wealthy clients of all nationalities. As he became aware of his own emotional labor and that of his colleagues, he grew interested in researching the emotional aspects of hospitality employees' job service. To minimize bias, he conducted initial research that was subsequently examined by the second and third authors, who did not participate in data collection but directed the theoretical and analytical phases, shaping the data analysis and interpretation. 


\section{Shortened Title: Coping with Emotional Labor}

Owing to the limited number of casinos in [location withheld], precise locations of the casinos will not be identified to protect the participants' anonymity and confidentiality.

Participants were frontline employees currently working or have worked in VIP rooms' food and beverage department. The private nature of VIP rooms made contacting these employees difficult (Wang \& Eadington, 2008). To gather sufficient suitable participants, a combination of purposive, convenience and snowball sampling approaches were employed (Creswell, 2013).

Six participants were invited through direct social media (Facebook) and cellphone messages. To gather more responses, the fieldwork researcher then drew on his membership in a social media page that limits membership to VIP rooms' frontline employees. An invitation was posted on the page, and three participants responded and participated. A subsequent eleven participants were referred to the researcher by the initial nine participants. Data was sequentially analyzed between interviews and saturation occurred at 20 participants when no new themes were found. Of 20 participants, seven were former employees who had left the VIP environment within the previous six months. Participants' age ranged from 21 to 41 years, and a ratio of 11:9 females to males. Eight had a year or less of experience as a VIP room frontline employee (please see Appendix 1 for participants' profile). We acknowledge the lack of work experience in this sample profile as a limitation, reflecting the high turnover faced by hospitality organizations.

Informed consent packages were provided prior to the interviews, and participants' identity was masked. Mock interviews were conducted, and irrelevant questions were removed or revisited. Each interview started with questions on the participant's background, the nature of the work environment, and the participant's feelings when working in the environment (please see Appendix 2 for interview questions). The interviews explored participants' interactions with guests and colleagues and were probed on how they cope with 


\section{Shortened Title: Coping with Emotional Labor}

difficult situations. Interviews lasted between 30 to 90 minutes and were digitally recorded and transcribed.

Thematic analysis allowed us to categorize data and find trends and patterns relating to participants' lived experiences (Clarke \& Braun, 2016); it is commonly used by tourism and hospitality researchers (Kwek, Wang, \& Weaver, 2014; Wang, Weaver, \& Kwek, 2015). Analysis of the data employed the open, axial, and selective coding procedure (Figure 2) (Strauss \& Corbin, 1998). Codes were constantly compared, as specific behaviors found were contrasted with other labels to decide a suitable fit. From this process, similar traits (theoretical properties) materialized. For example, "faking a professional persona" and "fake smile" were categorized as "faking behavior". The category "faking behavior" was further supplemented by a succinct description: "faking a behavior or suppressing genuine feelings in order to fit with organizationally desirable behaviors (smiling, happiness, and/or excitement)" (Ashforth \& Humphrey, 1993).

Please insert Figure 2 about here

\section{Results}

Q1: What key coping strategies do VIP rooms' frontline employees use to cope with emotional labor?

Figure 3 depicts 16 strategies in four families that frontline employees employ to cope with emotional labor. Negative or positive outcomes patterns emerged from the four families of coping strategies. Opposition and rumination had negative outcomes, whereas emotional regulation and positive cognitive restructuring had positive outcomes. Please insert Figure 3 about here

\section{Opposition Strategies}

These are overt and negative forms of coping strategies that participants use to mitigate stress. Employees adopt these strategies to cope with stress quickly and to continue 


\section{Shortened Title: Coping with Emotional Labor}

performing their required tasks. Within this family, coping strategies include avoidance, deflecting, emotional out-letting, and confrontation. These strategies are observed to occur when participants want to protect their autonomy (well-being), in immediate emotional demanding situations when there is low perceived control; it is also genuine emotions (that are deviant) which achieve instantaneous reactions.

Avoidance. Physically or emotionally removing oneself from a stressful situation.

One participant described how she would detach herself from a stressful encounter:

I don't want to argue with the guest, that's why I would not show my feelings; if I do feel uncomfortable, I'll just walk away from them... because I'll become too emotional (well-being). (P6, female)

Deflecting. Transferring responsibility or blame away from themselves. They may redirect the focus to someone or something else, aiming to take themselves out of the scenario. A participant recalled that when denying guests' requests, she redirected the guests' displeasure to the organizational policy.

If guests pester me for something they aren’t eligible for, I say, “Sorry. I can't get that for you, because of our strict company policies.” (P2, female)

Emotional out-letting. Expressing grievances away from guests - that is, releasing emotions verbally or through facial expressions (e.g. swearing, crying, or eye rolling).

When you go around the corner from the guests, you roll your eyes... You swear under your breath or something... I've seen some people break down. Some people have been yelled at. They get flustered and emotional. Some cry. It gets to them, because they treat you like a slave (well-being). (P5, male)

Confrontation. Retaliation against stressors by raising their voice or directly challenging the stressor if participants are unable to control their emotions. One participant confronted an irascible guest by standing his ground and challenging the guest to make a 


\section{Shortened Title: Coping with Emotional Labor}

complaint when the guest demanded a privilege that was beyond the guest's membership tier. In this case, the participant opted to protect his own feelings (well-being) instead of his relationship (relatedness) or service (competence) to the customer, as the customer subsequently complained to the manager about his behavior.

When the guest starts to raise his voice on me, I encouraged him to go complain... I told him in his face that if he continues with that attitude, I will refuse to provide him service. (P15, male)

While avoidance, deflecting and emotional out-letting may not be considered as deviant genuine emotions in everyday life, they are deviant in terms of professionalism. Especially in a customer service environment, these behaviors contradict the organization's required displays, and thus, classified as opposition strategies in this study.

\section{Rumination Strategies}

Rumination strategies justifies the situation or one's own emotions towards the situation to continue performing one's expected tasks. These strategies include faking behavior, reasoning, resignation, and apathy. Stress are internalized and dealt with by oneself. Individuals may not express their grievances; thus, others may not be able to tell that the frontline employee is coping with stress. Hence, competence is protected whilst potentially sacrificing any relatedness or autonomy. For instance, when frontline employees use reasoning to justify how "the benefits outweigh the negatives", they can carry on with their tasks. If feelings of helplessness continue, employees may feel even more emotionally exhausted.

Faking behavior. Faking a behavior or suppressing feelings to fit with organizationally desirable behaviors (Ashforth \& Humphrey, 1993). One participant stated that faking behavior allowed her to cope with emotional labor, enabling her to provide services. 


\section{Shortened Title: Coping with Emotional Labor}

Yeah, just fake it. If I'm stressed or annoyed or whatever, I'll still be like, "Hey, how are you going, sir?” ...That's your job (service performance). People who can't mask their emotions shouldn't be dealing with guests because, at the end of the day, we must come to work. (P1, female)

Reasoning. Attempts to rationalize the situation or the stressor to mitigate stress. One participant practiced reasoning to explain why he enjoyed his job despite the emotional labor: Oh, it's frustrating, but you know, the pay and benefits are good. People I work with are good. That outweighs the negatives to me... it allows me to do my job. (P5, male) Resignation. When participants feel compelled to accept the situation as it is. For example, a participant was frustrated with the number of hours he was allocated as a casual employee, as it created difficulties for him to get consistent pay.

That's their right as a big business, so you can't argue with it... Make sure you're there on time, just follow the rules and do your job... Teaspoon of cement. Harden up, you don't have a choice... everyone's doing a lot more overtime than what they used to... we're just so burnt out (well-being). (P4, male)

Apathy. Removal of emotions from the situation, or emotional detachment. Many participants admitted to adopting apathy toward their guests as a form of coping.

When it comes to work, I just turn off my emotions. Personal life and work life are different. Turn it off to succeed in your work life and turn it back on when you walk out the door (autonomy). (P5, male)

\section{Emotional Regulation Strategies}

Emotional regulation consists of feeling alignment, self-control, empathy, and diversion. These strategies are used in situations that require swift coping strategies to produce more positive outcomes but require more effortful psychological modifications. Participants try to balance between autonomy, competence and relatedness and may feel less 


\section{Shortened Title: Coping with Emotional Labor}

emotionally exhausted. When a frontline employee can interact with guests in a less scripted and more natural manner, the amount of emotional labor decreases and service performance improves (Hoffman, 2015).

Feeling alignment. Efforts to feel emotions that align with the required behavior (Hochschild, 1983). A participant described his tendencies to be cheerful at work regardless of his personal issues, to improve the general atmosphere in his workplace and guests' experience.

If I've got a problem or I'm sad about something I set it aside... whenever I'm at work I always try to be happy (well-being) ...Usually, I'm the one that tries to lighten up the mood of everybody (relatedness). (P3, male)

Self-control. Entails active regulation of one's emotions to de-fuse the situation, regardless of external forces. A participant recounted an episode where she was unfairly reprimanded by her manager.

The manager saw my untidy section and began yelling at me. She was being rude when I was trying to explain... I think it was unfair and it hurt me. After that I went: “Okay, I'll control my emotions (well-being), I'll keep working (service performance) .." (P11, female)

Empathy. Understanding the situation from another's point of view. Frequently, guests treat participants like therapists and relate their personal problems to the employees, regardless of whether the employee is interested.

It's being empathetic towards the members (relatedness)... If you're not comfortable with it, then you're in the wrong profession. Sort of over time I could handle it... Over time you become better at being empathetic, and knowing what to or not to say, to make guests feel better (competence). (P13, male) 


\section{Shortened Title: Coping with Emotional Labor}

Diversion. Diverting attention from stress through others. Participants stated that their positive interactions with guests, such as jokes or pleasant conversations, restored their emotional resources.

If it wasn't too busy I'd just go up there and start shooting the shit with them (relatedness), just joking around. Then yeah, sort of... I could just spend more time with them, and be more natural, which was enjoyable when you're just talking to people... it didn't feel like a job (competence). (P13, male)

\section{Positive Cognitive Restructuring Strategies}

This family of strategies includes: constructive behavior, differentiation, social activities, and positive framing. These strategies are self-focused and emphasize the improvement of personal well-being in situations where stress is persistent with no immediate resolution. In this case, whilst the main objective is to protect one's autonomy and wellbeing, participants tried not to compromise their competence or relatedness. For example, instead of subjecting themselves to rumination strategies, they decide to use this strategy to achieve better outcomes for themselves.

Constructive behavior. Channeling energy from negative emotions into productive behavior. For example, a participant channeled her stress from long work hours and dislike of cleaning duties into efficiency.

Seven and a half hours of work is not much anymore... So, if I spread it out between servicing guests, cleaning the buffet and coffee area, then service again (service performance) ... it keeps me very occupied... It's an effective way to spend a day at work without being bored (well-being). (P8, female)

Differentiation. Formation of boundaries by distinguishing work from home or differentiating feelings for team members from feelings for guests. A participant indicated that he did not greet guests when he encounters them outside of the workplace. 


\section{Shortened Title: Coping with Emotional Labor}

So even if I know them very well, ...but if I see them in my private time... I just ignore them. Because they are having their private time, I am having my private time (well-being). Guest is a guest... (P16, male)

Social activities. Activities outside of work to cope with stress, such as socializing with friends or playing sports. Working in VIP rooms makes socializing difficult because of irregular work schedules and graveyard shifts. Therefore, most frontline employees begin to form social circles within their workplace. One participant noted that he enjoys meeting with friends and engaging in sports.

When I get out from work, I participate in sports... Sometimes when I need to talk to someone, I get a drink with a colleague (relatedness). Then you think, and you talk through the problems that happen (well-being). (P3, male)

Positive framing. Refers to thinking of a stressful situation positively. A participant framed her mindset to see the positive in working block shifts with unreasonable hours.

Once you're there you can kind of keep going for an extra few hours (service performance). I'd rather go in and do a solid block then have three days off, than having to come in for tiny blocks all the time (well-being). (P9, female)

Q2: In what circumstances do VIP rooms' frontline employees utilize one coping strategy over another with respect to emotional labor?

\section{Emotional demand and perceived control situations}

Participants were observed to frequently characterize stress in terms of whether it was immediate or persistent, mentioning that the job is "always" or "sometimes" stressful. Immediate emotional demand situations require immediate attention, such as understaffing, equipment malfunctions, and verbally abusive guests. Persistent emotional demands happen continuously and are aspects beyond employees' control, such as lazy team members or inflexible organizational policies. Additionally, analysis revealed two perceived control 


\section{Shortened Title: Coping with Emotional Labor}

situations - high or low - which are based on the control levels the individuals exercise over the situation or their emotions (Meier et al., 2008). Opposition and rumination were observed to occur when perceived control was low, whereas emotional regulation and positive cognitive restructuring occurred when perceived control was high. A combination of emotional demands and perceived control were observed in four scenarios in this study, each associated with a distinct set of coping strategies.

\section{Immediate emotional demand situation with low perceived control}

Participants tend to adopt an opposition strategy and portraying their deviant genuine emotions under this type of situation, as exemplified in the case below. A participant was asked about the environment she was working in, recalling instances where she was verbally abused by a guest and felt out of control over the situation. P10, female, describes her experience:

I think the hardest part is the gambling and high maintenance customers... if you turn up and they haven't won, they divert their anger at you... It's an emotional place. You could walk in super happy, five seconds later, someone might scream at you for nothing... Your day would totally change.

When asked how she copes in such a situation which she has no control over, she replied:

Personally, I would walk away (avoidance). I'll try to ask to go home early, or I'll go vent to another colleague... venting about how shit that person is (venting).

In this situation, P10, female, used an opposition strategy to cope with the immediate emotional demands. Choosing to protect one's autonomy and well-being by avoiding a customer and venting (emotional out-letting) are forms of coping that are in direct opposition to the organization's display rules (deviant genuine emotions).

\section{Immediate emotional demand situation with high perceived control}




\section{Shortened Title: Coping with Emotional Labor}

Other times, participants may face immediate emotional demand but feel in total control over the situation. The following case depicts how the employee adopts an emotional regulation strategy and deep acting to deliver professionalism. P1, female, describes her experience:

The hotbox last night wasn't working... Congee and soups come 40 minutes beforehand until we serve it. Obviously, it's gotten cold. As we're serving it, people are complaining: "La la, it's cold, la la."

P1, female, then describes her thought process during that situation:

... the best way is to empathize (empathy) with them. I let them [customers] rant, ...then go, "Okay. I see where you're coming from, but, unfortunately, I can't give you hot soup right now. I will have it soon if you can patiently wait."... I had to pretty much stop myself and go, "Okay, I need to think about what's going on, what needs to happen. I evaluate everything and go, "Okay, these things need to happen." (selfcontrol)

In this situation, P1, female, had higher perceived control over the situation. As such, she used self-control to protect her well-being and empathy to protect her relatedness with the customer, which are emotional regulation strategies. By empathizing with the customer, it is a form of deep acting that allows professional interaction (protecting her competence) with the complaining guest.

\section{Persistent emotional demand situation with low perceived control}

Occasionally, employees may face persistent emotional demands and feel a lack of perceived control. The following case describes how the employee adopts rumination strategies and must surface act under this situation. P4, male, describes:

Being in a casual 24-hour roster, we can't really have a life... There's no regularity... you can't plan anything... You must dedicate yourself if you want to keep up with 


\section{Shortened Title: Coping with Emotional Labor}

rent, or if you want to buy a house or something, you must flog yourself to the bone until you're exhausted.

He further adds:

...It doesn't matter how you feel, you must switch off [emotions] and go into your service mode (apathy). That's what the company and guests want... switch off emotionally (resignation).

P4, male, felt low perceived control over the situation and employed apathy and resignation, which are rumination strategies. This allowed him to continue providing service to his guests (competence), through surface acting, even though he felt stressed at work.

\section{Persistent emotional demand situation with high perceived control}

There may be times where employees have higher perceived control over their emotions, although they conceive the situation as uncontrollable. In such situations, participants adopt positive cognitive restructuring and can portray their aligned genuine emotions. P15, male, describes:

The company's cutting hours and putting massive workloads on us... The caring employees are getting more frustrated because they care about the place, but the guests are not happy anymore. That's why we're less busy [as compared to the past], that means there's less people, less guests.

When asked how he copes with the frustration he feels, he adds:

...when I come to work, ...I never bring my personal life to work (differentiation). You are the real, but not, the real you... I try to bring joy and happiness with me because with customer service you need to be welcoming (service performance).

In this case, $\mathrm{P} 15$, male, decided that employing differentiation, a form of positive cognitive restructuring, allows him to be his real, but different self, at work. This allows him 


\section{Shortened Title: Coping with Emotional Labor}

to bring more aligned genuine emotions with him to work that aligns with the required emotional displays.

\section{Discussion and conclusion}

\section{Summary and discussion of findings}

This study identified four sets of coping strategies that were associated with the different levels of control perceived by employees (low or high) and emotional demands (immediate or persistent) (Figure 2). VIP rooms can be chaotic and cause a range of emotionally demanding situations. In some situations, the frontline employees' perceived control may be low, and they may adopt an opposition strategy. Occasionally, more capable frontline employees take control of immediate emotionally demanding situations by using emotional regulation. Other times, where the perceived control is low, frontline employees may use rumination to cope. In contrast, frontline employees perceiving higher levels of control over persistent emotional demands would use positive cognitive restructuring to cope. The lower the perception of control, the likelier resulting consequences are negative.

This study found four categories of coping strategies associated with different staff well-being and operational outcomes, aligning with Skinner et al.'s (2003) approach that motivational priorities may affect the type of coping strategy used. Participants adopting opposition or rumination potentially faced negative consequences to their autonomy (wellbeing), competence (service performance), and relatedness (relationships), while those adopting emotional regulation and positive cognitive restructuring had positive outcomes. This research further advanced Skinner et al.'s (2003) approach by revealing that the possession of two or more motivational priorities potentially leads to more positive coping strategies. In Figure 4, the left quadrants represent negative coping strategies and the right quadrants positive coping strategies. 


\section{Shortened Title: Coping with Emotional Labor}

Current emotional labor coping literature in hospitality has adopted a quantitative methodology (Pienaar \& Willemse, 2008; Tsaur \& Tang, 2012). From a qualitative perspective, this study looked at how casino employees' cope with emotional labor (Edwards, 1992) and found that coping strategies may influence the emotional labor enactment. First, opposition appeared to escalate deviant genuine emotions that defy the organization's display rules. In this study, when the employee confronts and challenges a guest to make a complaint (deviant genuine emotions), it goes against the professional etiquette of a hospitality employee. Moreover, the study found that motivational priorities play a role in coping strategies. In an immediate emotional demand situation with low perceived control, employees may feel compelled to temporarily protect their autonomy (well-being), disregarding their competence (service performance) and relatedness (relationships). However, they may feel more emotionally exhausted as they fear being reprimanded by upper management. Therefore, while there are temporary improvements to well-being and negative outcomes to service performance and relationships, ultimately, all three outcomes suffer.

Contrary, emotional regulation may encourage deep acting. When competence and relatedness are valued during immediate emotional demand and high perceived control situations, autonomy may be adjusted accordingly. For example, when an employee feels that a guest is complaining excessively, the employee copes by being empathetic and showing sympathy (deep acting) towards the guest. By doing so, competence and relatedness are protected, while ultimately improving their autonomy as well. Hence, temporary negative aggravations towards their well-being and positive outcomes to their service performance and relationships are experienced. In the long-term, all three outcomes improve.

Rumination potentially encourages surface acting. In this family, strategies are covert and detrimental to well-being. The employee values competence and relatedness but are unable to adjust their autonomy due to lowered perceived control. For instance, when 


\section{Shortened Title: Coping with Emotional Labor}

employees use reasoning to rationalize their work emotional demands, they would still perform their duties through surface acting, leading to temporary positive service performance and relationships. However, as emotional dissonance experienced increases over time, well-being, service performance and relationships suffer.

Finally, positive cognitive restructuring reinforces aligned genuine emotions. When autonomy and competence or relatedness are valued, solutions outside of work may be used to ensure that all the three factors are well balanced. When an employee differentiates and separates life and work instances, they develop a stronger sense of control over themselves; thus, produces aligned genuine emotions when interacting with others. This is also dependent on whether they experience any immediate emotional demands during an interaction.

Ultimately, aligned genuine emotions result in better autonomy, relatedness or competence.

In short, the above offers answers to an important question on how perceived control and motivational priorities affect the non-dyadic hierarchical coping strategies that Skinner et al. (2003) initially proposed. Clearly, the set of coping strategies a person adopts varies according to perceived control and what the person prioritizes.

\section{Theoretical contributions}

This study differs from past emotional labor coping studies and makes significant contributions by focusing on coping strategies that could influence the emotional labor enactment (surface acting, deep acting, and genuine emotions). Our analysis breaks down the emotion management process and highlights how surface acting, deep acting, and genuine emotions occur in a work environment. Our model (Figure 4) presents an opportunity to develop further studies to help identify effective emotional labor coping strategies.

This study expands the understanding of competence, relatedness, and autonomy in the coping process. Although these priorities were not used for categorization in our model, they affect the type of strategy used (Visser, 2010). Therefore, participants' coping strategy 


\section{Shortened Title: Coping with Emotional Labor}

would depend on how they prioritized their well-being (autonomy), service performance (competence), or relation to guests or team members (relatedness) (Skinner et al., 2003). Moreover, it was found that if two or more of the motivational priorities were selected, participants adopt more positive coping strategies.

Additionally, this study adds to the theoretical foundations of Skinner et al.'s (2003) study. Opposition, rumination, emotional regulation and positive cognitive restructuring were identified as strategies used by participants in this study and confirm that the non-dyadic distinction is suitable for future research. Within these four higher order coping strategies, we further clarified the lower order coping strategies in these respective families. Our findings do not completely conform to Skinner et al.'s (2003) categories, a result we believe stems from the specific context of hospitality being service oriented and highly interactive. For example, Avoidance, which in Skinner's research is a family of its own, in our research is a part of Opposition, because walking away from an angry customer (avoidance) most likely will further antagonize the customer, affecting service performance.

We further categorized the coping strategies that can potentially influence the enactment of emotional labor. These strategies were divided based on emotional demands and perceived control, emphasizing how perceived control can lead to positive coping (emotional regulation and positive cognitive restructuring) and emotional labor enactment (deep acting and aligned genuine emotions). By introducing coping as a potential moderator of the emotional labor enactment process, this study provides insight into the underlying emotion management not seen in previous emotional labor studies.

\section{Managerial implications}

Our study links coping strategies to emotional labor outcomes of staff well-being, service performance, and relationships. Depending on perceived control, employees may utilize either positive (i.e., those leading to better outcomes) or negative coping strategies 


\section{Shortened Title: Coping with Emotional Labor}

(i.e., those leading to worsened outcomes). Casinos should facilitate the use of positive coping strategies to provide a supportive work environment. Our recommendation is to ensure clear guest and staff policies, reducing confusion and role ambiguity (Karatepe, 2006). This would increase frontline employees' ability to take control and assume positive coping strategies in a demanding situation. Furthermore, organizations can encourage frontline employees' independence by giving employees more discretion in service recovery (Hocutt \& Stone, 1998). Organizations could also adopt mobile applications (Solis, 2017), providing real-time support or bite sized policies and procedures for staff and develop online spaces for employees to clarify policies and procedures.

Our findings also suggest the implementation of recreational programs, potentially lessening illness-related absences (Parks \& Steelman, 2008). A recent study has shown that casino employees partaking in leisurely activities were happier people, which translated into the workplace (Naude, Kruger, De Beer, Saayman, \& Jonker, 2016). Such social activities provide avenues for employees to destress and engage with positive coping strategies, developing a balanced work-life culture. They also foster camaraderie between team members, which can create good support systems within the organization and may indicate that their organization values and supports them (Rhoades \& Eisenberger, 2002).

Additionally, we recommend casinos to better equip employees with soft skills that encourage better interactions. Our findings depict that emotional regulation and positive cognitive restructuring are used when employees prioritize competence (service performance) and relatedness (relationships), which is influenced by competent soft skilled employees. Skilled employees would perceive higher control over stressful situations and are more likely to resort to positive coping strategies. Organizations should hold frequent scenario-based training workshops for employees with learning outcomes and objectives, aimed at improving soft skills (Ritter, Small, Mortimer, \& Doll, 2017). Moreover, organizations need to be 


\section{Shortened Title: Coping with Emotional Labor}

innovative and introduce collaborative learning experiences (Chowhan, Pries, \& Mann, 2016), and facilitate the use of it to improve these skills. For example, technologically assisted service simulation training programs that allows for blended learning (Ragg \& Piers, 2017), allows employees to develop these soft skills at their own pace.

\section{Limitations and future studies}

This research is limited in several ways. First, it only studied frontline employees working in VIP rooms, specifically, food and beverage attendants. Future studies can further develop the model to encompass employees in other high-stress hospitality sectors. For example, studies conducted in a local club may find similar emotional labor coping strategies. For instance, a sporting club may also be considered high stress environment since alcohol and gaming are involved, and patrons, often regulars, expect high levels of service consistency.

Second, while the study identified 16 strategies, their relative adoption is not clear, e.g., whether one coping strategy is used more than another (i.e. do frontline employees use avoidance more than confrontation in a low perceived control situation?).

Third, this research did not differentiate between different stress factors such as the frontline employees' frustration with their management, team members, and guest and work environment. Fourth, the research did not consider the role of personality, self-perception, demographics and emotional intelligence in determining an employee's tendency to use one strategy over another, and to what extent. All these point to promising directions for future research.

Finally, future studies can consider whether the independent strategies within the four families can be scaled in terms of outcome severity. For example, in emotional regulation, which strategy produces the most positive impact in each situation? These studies will help identify the preferred strategy in each situation. Progress in this area of research will allow 
Shortened Title: Coping with Emotional Labor

researchers to gain a better understanding of the emotional labor coping strategies employees use and the breakdown of emotion management, which would benefit the industry. 


\section{References}

Adan, A., Antunez, J. M., \& Navarro, J. F. (2017). Coping strategies related to treatment in substance use disorder patients with and without comorbid depression. Psychiatry Research, 251, 325-332.

Amirkhan, J., \& Auyeung, B. (2007). Coping with stress across the lifespan: Absolute vs. relative changes in strategy. Journal of Applied Developmental Psychology, 28(4), 298-317.

Ashforth, B. E., \& Humphrey, R. H. (1993). Emotional labor in service roles: The influence of identity. Academy of Management Review, 18(1), 88-115.

Baumeister, R. F., \& Leary, M. R. (1995). The need to belong: Desire for interpersonal attachments as a fundamental human motivation. Psychological Bulletin, 117(3), 497529.

Brotheridge, C. M., \& Grandey, A. A. (2002). Emotional labor and burnout: Comparing two perspectives of "people work". Journal of Vocational Behavior, 60(1), 17-39.

Chan, S. H., Wan, Y. K. P., \& Kuok, O. M. (2014). Relationships among burnout, job satisfaction, and turnover of casino employees in Macau. Journal of Hospitality Marketing \& Management, 24(4), 345-374.

Cheng, S., \& Wong, A. (2015). Professionalism: A contemporary interpretation in hospitality industry context. International Journal of Hospitality Management, 50, 122-133.

Cheng, T.-M., Chang, S.-Y., \& Chan, Y.-Y. (2018). I know you are suffering from burnout: The moderated mediation effects of "leisure benefits"and "leisure coping"on the burnout model of flight attendants. Journal of Air Transport Management, 71, 119129. doi:10.1016/j.jairtraman.2018.06.003

Chowhan, J., Pries, F., \& Mann, S. (2016). Persistent innovation and the role of human resource management practices, work organization, and strategy. Journal of Management \& Organization, 23(03), 456-471.

Chu, K. H., Baker, M. A., \& Murrmann, S. K. (2012). When we are onstage, we smile: The effects of emotional labor on employee work outcomes. International Journal of Hospitality Management, 31(3), 906-915.

Clarke, V., \& Braun, V. (2016). Thematic analysis. The Journal of Positive Psychology, 12(3), 297-298.

Compas, B. E., Connor-Smith, J. K., Saltzman, H., Thomsen, A. H., \& Wadsworth, M. E. (2001). Coping with stress during childhood and adolescence: Problems, progress, and potential in theory research. Psychological Bulletin, 127(1), 87-127.

Creswell, J. W. (2013). Qualitative inquiry \& research design: Choosing among five approaches (3rd ed.). Los Angeles, CA: SAGE Publications.

Diefendorff, J. M., Croyle, M. H., \& Gosserand, R. H. (2005). The dimensionality and antecedents of emotional labor strategies. Journal of Vocational Behavior, 66, 339 357. doi:10.1016/j.jvb.2004.02.001

Edwards, J. R. (1992). A cybernetic theory of stress, coping, and well-being in organizations. The Academy of Management Review, 17(2), 238-274.

Golparvar, M. (2015). Unconventional functions of deviant behaviors in the relationship between job stress and emotional exhaustion: Three study findings. Current Psychology, 35(3), 269-284.

Goussinsky, R. (2015). Customer aggression, felt anger and emotional deviance: The moderating role of job autonomy. International Journal of Quality and Service Sciences, 7(1), 50-71.

Grandey, A. A., \& Gabriel, A. S. (2015). Emotional Labor at a crossroads: Where do we go from here? Annual Review of Organizational Psychology and Organizational Behavior, 2(1), 323-349. 
Hochschild, A. R. (1983). The managed heart. Berkeley: University of California Press.

Hocutt, M. A., \& Stone, T. H. (1998). The impact of employee empowerment on the quality of service recovery effort. Journal of Quality Management, 3(1), 117.

Hoffman, E. A. (2015). Emotions and emotional labor at worker-owned businesses: Deep acting, surface acting, and genuine emotions. The Sociological Quarterly, 57, 152173.

Hoffman, E. A. (2016). Emotions and emotional labor at worker-owned businesses: Deep acting, surface acting, and genuine emotions. The Sociological Quarterly, 57(1), 152173. doi:10.1111/tsq.12113

Jeung, D.-Y., Kim, C., \& Chang, S.-J. (2018). Emotional labor and burnout: A review of the literature. Yonsei Medical Journal, 59(2), 187-193. doi:10.3349/ymj.2018.59.2.187

Karatepe, O. M. (2006). The effects of selected antecedents on the service recovery performance of frontline employees. The Service Industries Journal, 26(1), 39-57.

Kenworthy, J., Fay, C., Frame, M., \& Petree, R. (2014). A meta-analytic review of the relationship between emotional dissonance and emotional exhaustion. Journal of Applied Social Psychology, 44, 94-105. doi:10.1111/jasp.12211

Kwek, A., Wang, Y., \& Weaver, D. B. (2014). Retail tours in China for overseas Chinese: Soft power or hard sell? Annals of Tourism Research, 44, 36-52.

Lazarus, R. S., \& Folkman, S. (1984). Stress, appraisal, and coping. New York: Springer Publishing Company.

Lee, C., An, M., \& Noh, Y. (2014). The effects of emotional display rules on flight attendants' emotional labor strategy, job burnout and performance. Service Business, 9(3), 409-425.

Lu, A. C. C., \& Gursoy, D. (2013). Impact of job burnout on satisfaction and turnover intention: Do generational differences matter? Journal of Hospitality \& Tourism Research, 40(2), 210-235.

Lucas, A. F., Kilby, J., \& Santos, J. (2002). Assessing the profitability of premium players. Cornell Hotel and Restaurant Administration Quarterly, 43(4), 65-78.

Luchman, J. N., \& Gonzalez-Morales, M. G. (2013). Demands, control, and support: A metaanalytic review of work characteristics interrelationships. Journal of Occupational Health Psychology, 18(1), 37-52.

Meier, L. L., Semmer, N. K., Elfering, A., \& Jacobshagen, N. (2008). The double meaning of control: three-way interactions between internal resources, job control, and stressors at work. Journal of Occupational Health Psychology, 13(3), 244-258.

Morling, B., \& Evered, S. (2006). Secondary control reviewed and defined. Psychological Bulletin, 132(2), 269-296.

Naude, R., Kruger, S., De Beer, L. T., Saayman, M., \& Jonker, C. (2016). The relationship between personality types and leisure time activities amongst Casino employees' workplace expectations. SA Journal of Human Resource Management, 14(1), 1-11. doi:10.4102/sajhrm

Ntoumanis, N., Edmunds, J., \& Duda, J. L. (2009). Understanding the coping process from a self-determination theory perspective. British Journal of Health Psychology, 14(2), 249-260.

Olson, K. (2011). Essentials of qualitative interviewing. Walnut Creek, CA: Left Coast Press, Inc.

Parks, K. M., \& Steelman, L. A. (2008). Organizational wellness programs: A meta-analysis. Journal of Occupational Health Psychology, 13(1), 58-68.

Pienaar, J., \& Willemse, S. A. (2008). Burnout, engagement, coping and general health of service employees in the hospitality industry. Tourism Management, 29(6), 10531063. 
Ragg, M., \& Piers, J. (2017). Competency-based blended learning: Flipping professional practice classes to enhance competence development. IAFOR Journal of Education, 5(SI), 47-66.

Reyers, A., \& Matusitz, J. (2012). Emotional regulation at Walt Disney World: An impression management view. Journal of Workplace Behavioral Health, 27(3), 139159.

Rhoades, L., \& Eisenberger, R. (2002). Perceived organizational support: A review of the literature. Journal of Applied Psychology, 87(4), 698-714.

Riley, M. (2007). Role interpretation during service encounters: A critical review of modern approaches to service quality management. International Journal of Hospitality Management, 26(2), 409-420.

Ritter, B. A., Small, E. E., Mortimer, J. W., \& Doll, J. L. (2017). Designing management curriculum for workplace readiness: Developing students' soft skills. Journal of Management Education, 42(1), 80-103.

Sanchez, D., Smith, L. V., \& Adams, W. (2018). The relationships among perceived discrimination, marianismo gender role attitudes, racial-ethnic socialization, coping styles, and mental health outcomes in Latina college students. Journal of Latina/o Psychology, 6(1), 1-15.

Sandiford, P. J., \& Seymour, D. (2011). Reacting to the demands of service work: Emotional resistance in the Coaching Inn Company. The Service Industries Journal, 31(8), 1195 1217.

Shani, A., Uriely, N., Reichel, A., \& Ginsburg, L. (2014). Emotional labor in the hospitality industry: The influence of contextual factors. International Journal of Hospitality Management, 37, 150-158.

Skinner, E. A., Edge, K., Altman, J., \& Sherwood, H. (2003). Searching for the structure of coping: A review and critique of category systems for classifying ways of coping. Psychological Bulletin, 129(2), 216-269.

Slevitch, L. (2011). Qualitative and quantitative methodologies compared: Ontological and epistemological perspectives. Journal of Quality Assurance in Hospitality \& Tourism, 12(1), 73-81.

Sloan, A., \& Bowe, B. (2013). Phenomenology and hermeneutic phenomenology: The philosophy, the methodologies, and using hermeneutic phenomenology to investigate lecturers' experiences of curriculum design. Quality \& Quantity, 48(3), 1291-1303.

Sohn, H.-K., Lee, T. J., \& Yoon, Y.-S. (2016). Emotional labor and burnout: Comparison between the countries of Japan and Korea. Journal of travel \& tourism marketing, 33(5), 597-612.

Solis, R. (2017). Employee training strategies for today's workforce. Strategic HR Review, $16(6), 250-254$.

Strauss, A., \& Corbin, J. (1998). Basics of qualitative research: Techniques and procedures for developing grounded theory. Thousand Oaks, CA: Sage Publications, Inc.

Subramony, M., Ehrhart, K., Groth, M., Holtom, B. C., van Jaarsveld, D. D., Yagil, D., ... Wirtz, J. (2017). Accelerating employee-related scholarship in service management. Journal of Service Management, 28(5), 837-865.

Tsaur, S.-H., \& Tang, Y.-Y. (2012). Job stress and well-being of female employees in hospitality: The role of regulatory leisure coping styles. International Journal of Hospitality Management, 31(4), 1038-1044.

Visser, C. (2010). Self-determination theory meets solution-focused change: Autonomy, competence and relatedness support in action. Journal of Solution Focus in Organizations, 2(1), 7-26. 
Walsh, G. (2018). Service employees' naturally felt emotions: Do they matter? European Management Journal, In Press, 1-8.

Wang, W., \& Eadington, W. R. (2008). The VIP-room contractual system and Macao's traditional casino industry. China: An International Journal, 6(2), 237-260.

Wang, Y., Weaver, D. B., \& Kwek, A. (2015). Beyond the mass tourism stereotype. Journal of Travel Research, 55(6), 724-737.

White, R. W. (1959). Motivation reconsidered: The concept of competence. Psychological Review, 66(5), 297-333.

Wong, I. A., \& Rosenbaum, M. S. (2012). Beyond hardcore gambling: Understanding why mainland Chinese visit casinos in Macau. Journal of Hospitality \& Tourism Research, $36(1), 32-51$. 